\title{
Perfil do professor mobile: uso de dispositivos móveis na docência
}

\author{
Mobile teacher profile: use of mobile devices in teaching
}

\author{
Anna Helena Silveira Sonego ${ }^{1 *}$, Nathalie Assunção Minuzi ${ }^{2}$, Aline Goulart Rodrigues ${ }^{3}$, \\ Leticia Rocha Machado ${ }^{4}$, Patricia Alejandra Behar ${ }^{5}$
}

\begin{abstract}
RESUMO
O objetivo desta pesquisa foi identificar as características que compõem o perfil do professor mobile, analisando suas potencialidades e fragilidades em relação ao uso de dispositivos móveis (DM) na docência. Neste estudo utilizou-se a metodologia do tipo descritiva, com uma abordagem qualitativa. O público-alvo foram 28 professores da Educação Básica e do Ensino Superior. O instrumento de coleta de dados foi um questionário on-line com perguntas objetivas e dissertativas. Os dados coletados e sua análise permitiram verificar que este público possui certa familiaridade com os DM, mas ainda apresentam algumas lacunas em relação ao seu uso de forma educacional. Sendo assim, verificou-se que o consumo de informações é umas das principais atividades realizadas, seguidas de compartilhamento de fotos, arquivos, acesso à internet e redes sociais. Em relação ao uso educacional, aponta-se que os professores utilizam na pesquisa de materiais para suas aulas, enviar e-mail ou mensagens para seus estudantes, entre outras ações. Logo, este trabalho possibilitou conhecer algumas características que compõem o perfil do professor mobile, indicando suas potencialidades e desafios frente ao uso dos dispositivos móveis na docência.
\end{abstract}

Palavras-chave: Dispositivos móveis; Perfil do professor; Educação Básica; Ensino Superior; M-learning.

\begin{abstract}
The objective of this research was to identify the characteristics that make up the profile of the mobile teacher, analyzing their strengths and weaknesses in relation to the use of mobile devices (MD) in teaching. In this study, a descriptive methodology was used, with a qualitative approach. The target audience was 28 teachers from Basic Education and Higher Education. The data collection instrument was an online questionnaire with objective and essay questions. The data collected and its analysis allowed us to verify that this public has some familiarity with the DMs, but they still have some gaps in relation to their use in an educational way. Thus, it was found that the consumption of information is one of the main activities carried out, followed by sharing photos, files, internet access and social networks. Regarding educational use, it is pointed out that teachers use it to research materials for their classes, send e-mails or messages to their students, among other actions. Therefore, this work made it possible to know some characteristics that make up the profile of the mobile teacher, indicating their potential and challenges facing the use of mobile devices in teaching.
\end{abstract}

Keywords: Mobile devices; Teacher profile; Basic education; Higher education; M-learning.

1, 2, 3, 4, 5 Universidade Federal do Rio Grande do Sul.

*E-mail: sonego.anna@gmail.com 


\section{INTRODUÇÃO}

O avanço das tecnologias digitais (TD) é perceptível em vários âmbitos da sociedade, como a economia, o mercado de trabalho e a educação. Neste último, no que concerne ao processo de ensino e aprendizagem percebem-se mudanças nas relações existentes entre os sujeitos com o uso dos recursos digitais, bem como com os dispositivos móveis (DM), conhecidos como smartphones e tablets. Segundo a UNESCO (2021, p.1), os DM são onipresentes, já que "Da população estimada da Terra, por volta de 7 bilhões de pessoas, 6 bilhões já têm acesso a um telefone móvel em funcionamento". É possível perceber o quanto os dispositivos têm ganhado espaço principalmente no contexto educacional. Esses aparelhos têm auxiliado cada vez mais os docentes tanto nos planejamentos, quanto na implementação de suas práticas pedagógicas. Desse modo, observa-se a existência de uma demanda em conhecer como esses professores utilizam, aprendem e compartilham suas ações mediadas pelo uso dos DM. Nesta perspectiva, este estudo pretende identificar as características que compõem o perfil do professor mobile, analisando suas potencialidades e fragilidades em relação ao uso de DM na docência. Para tanto, leva-se em consideração o fato de utilizar os dispositivos móveis, que são aparelhos portáteis, com acesso à internet e que possibilitam a realização de tarefas distintas, seja para uso pessoal, entretenimento, trabalho ou educacional.

De acordo com uma pesquisa divulgada em 2020 pelo Comitê Gestor da Internet no Brasil, o computador de mesa e notebook são dispositivos que perdem força frente ao celular, utilizado para acessar a rede de internet por 98\% dos alunos (CGI.BR, 2020). Diante deste cenário é necessário, cada vez mais, que os docentes mantenham-se atualizados quanto ao uso dos dispositivos móveis, especialmente, em relação aos smartphones. Sendo assim, estas demandas geram novos desafios e possibilidades para o processo de ensino e aprendizagem, proporcionando aos professores a diversificação do planejamento e desenvolvimento de atividades escolares com os dispositivos móveis. Além disso, no último ano, devido à pandemia COVID-19, a presença física nas escolas, universidades e instituições de Ensino Superior foram interrompidas devido às recomendações impostas pelo distanciamento social. Para tanto, as tecnologias tornaramse essenciais para mediar, dar continuidade e manter contato entre alunos e professores durante este período, que já perdura por mais de dois anos. 
Portanto, a integração das TD é uma temática que tem sido dialogada antes, durante e, possivelmente, continuará em pauta após a pandemia. Diante deste contexto, torna-se essencial conhecer sobre o perfil do professor mobile, mais especificamente professores do ensino básico e superior. Desse modo, reconhecer esse sujeito e suas características pode contribuir para o desenvolvimento de estratégias pedagógicas que venham auxiliar a contemplar os saberes construídos com à utilização das tecnologias.

Assim, este estudo apresenta como temática o mapeamento e a identificação do professor como sujeito mobile e as suas perspectivas em relação ao uso de forma geral e educacional dos dispositivos móveis. Para tanto, este artigo encontra-se dividido em cinco seções: a primeira trata da introdução do assunto. A segunda descreve o referencial teórico sobre o uso dos DM pelos professores. A terceira aponta o caminho metodológico da pesquisa. A quarta seção aponta os resultados e discussões dos dados e, por fim, são apresentadas as considerações finais.

\section{USO DOS DISPOSITIVOS MÓVEIS PELOS PROFESSORES}

O uso das tecnologias digitais nos ambientes escolares já não é uma novidade, já que há muitos anos alguns professores já fazem essa inserção nos seus planejamentos e nas suas práticas pedagógicas (VIDAL e MIGUEL, 2020). Com o avanço tecnológico tem-se realizado o uso dos dispositivos móveis como um recurso mediador no processo de ensino e aprendizagem, apresentando potencial para desenvolver a mobile learning (m-learning) ou aprendizagem móvel. Nesse sentido, compreende-se que esta pode ser entendida como "uma possibilidade de mediar atividades de estudo dentro e fora da sala de aula através dos dispositivos móveis, com base na definição de ensino híbrido" (SONEGO, 2019). É importante esclarecer que essa mediação pode ocorrer em qualquer modalidade e nível de ensino. Para tanto, faz-se necessário o uso dos DM, preferencialmente conectado a uma rede de internet, do tipo Wi-Fi, 3G, 4G ou 5G. Nesse sentido, a mobile learning pode gerar distintas situações para que ocorra a inovação e novas possibilidades de aprendizagem, em qualquer tempo e lugar, obtendo melhor aproveitamento do dispositivo para fins educacionais.

Sendo assim, considera-se que o professor que utiliza estes equipamentos nas suas aulas deve desenvolver ou aprimorar certos conhecimentos específicos, habilidades e atitudes em relação às suas funcionalidades e desafios que podem surgir. Diante desta perspectiva, admite-se que esse sujeito pode diferenciar-se quanto ao uso dos DM, tanto em relação às características pessoais como profissionais que podem decorrer do 
planejamento e aplicação de atividades com os dispositivos móveis. Sendo assim, acredita-se que um docente com essas particularidades exclusivas pode ser considerado como um professor mobile. Essa concepção vai ao encontro do que postula Krimberg (2019), no qual aponta que qualquer sujeito que aprenda a utilizar os dispositivos móveis pode vir a fazer parte desse grupo de indivíduos, ou seja, sujeitos mobile estão em constante contato com os DM.

Entretanto, cabe destacar que, em decorrência da pandemia mundial causada pelo vírus COVID-19, os professores tiveram que adaptar ou replanejar suas práticas para que pudessem dar continuidade às suas ações com aulas síncronas ou assíncronas por meio das TD e dos DM. Essa alternativa foi definida com base na portaria $n^{\circ} 343$ de 17 de março de 2020, em que o MEC indica que as aulas foram organizadas por meio de recursos tecnológicos utilizando internet, mídias digitais, smartphones e televisão (CRUB, 2020). Com efeito, os docentes tiveram que se reinventar e incluí-las nos seus planejamentos como um meio para dar sequência às aulas, manter-se próximos e em comunicação aos alunos, pais e comunidade escolar em geral. Diante deste contexto, os dados apresentados pelo Painel TIC COVID-19 (CETIC.BR, 2021) vão ao encontro dessa concepção, já que apontam que cada vez mais os smartphones estão sendo usados para o ensino remoto (ER), conforme mostra o gráfico 1.

Gráfico 1: Recursos utilizados para acompanhamento de aulas ou atividades remotas.

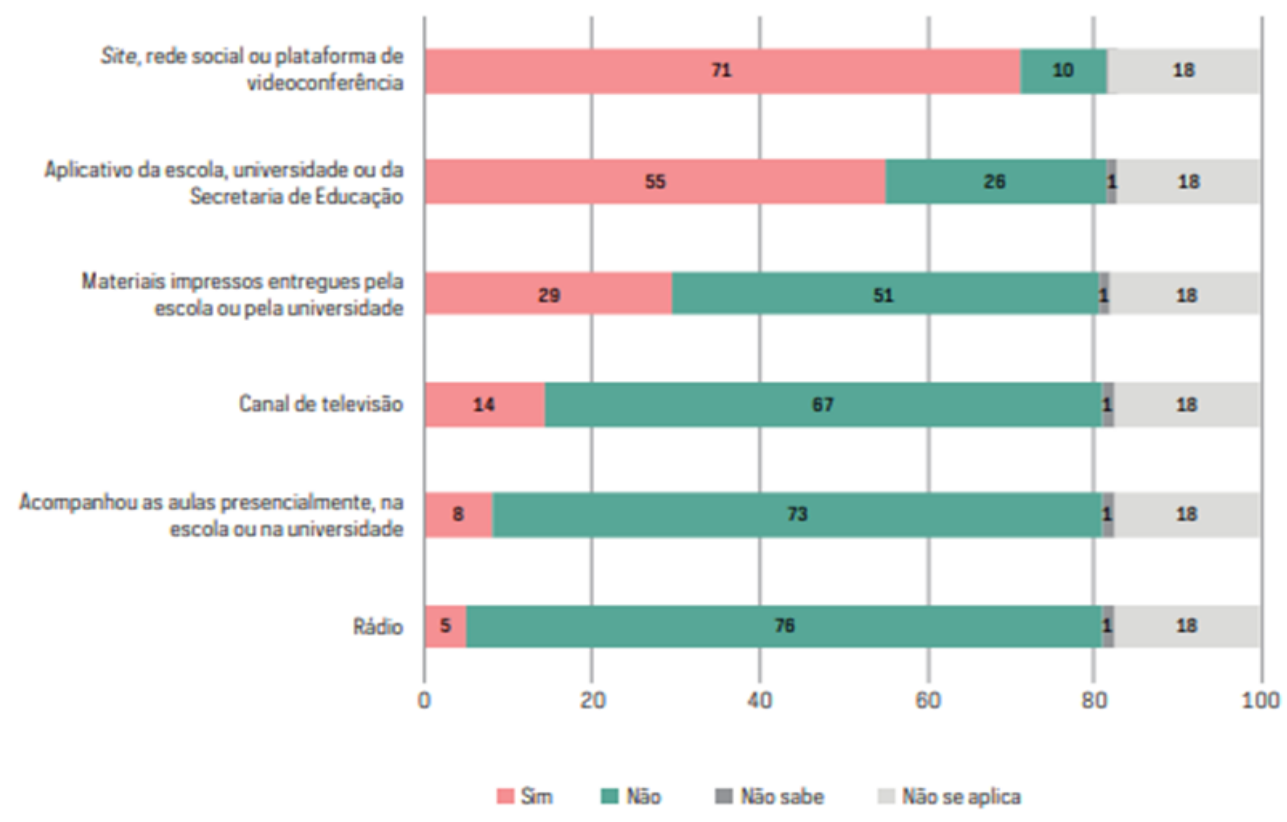

Fonte: CETIC.BR. (2021). 
De acordo com o gráfico 1, percebe-se que $71 \%$ dos usuários que acompanham as aulas ou atividades educacionais remotas acessaram tais conteúdos por meio de recursos digitais como website, rede social ou plataforma de videoconferência. Já os que acessam através de um aplicativo da escola, universidade ou Secretaria de Educação equivalem a $55 \%$. Destaca-se que a maior proporção dos usuários de Internet (42\%) passou de uma a três horas por dia participando das atividades educacionais remotas. De outro lado, 29\% dos pesquisados fizeram uso de materiais impressos entregues pela escola ou universidade para acesso aos conteúdos educacionais (CETIC.BR, 2021).

Essas informações corroboram com a temática do uso dos DM nas atividades escolares e fica emergente a demanda de que os professores estejam preparados para planejar e implementar atividades educacionais mediadas pelos dispositivos. Nesse sentido, admite-se que é imprescindível que, além de desenvolverem conhecimentos, habilidades e atitudes é necessário que esse docente se reconheça com as características e o perfil de um professor mobile. Para tanto, é relevante que esteja familiarizado e aberto às novas aprendizagens que advêm do ensino remoto, por exemplo. Mas, para isso, é pertinente conhecer quais seriam suas características, conforme apontado a seguir.

\section{METODOLOGIA}

A pesquisa adotada neste estudo é do tipo descritiva, com uma abordagem qualitativa. Esse tipo de abordagem foi escolhida a fim de identificar os fatores que determinam ou que contribuem para a ocorrência dos fenômenos (GIL, 1999). Além disso, permite que os fatos sejam registrados, analisados, classificados e interpretados, sem interferência do pesquisador. Para obter os dados para este trabalho fez-se o uso de técnicas padronizadas de coleta de dados a partir de um questionário on-line.

O público-alvo foi escolhido de forma aleatória, tendo como perfil professores pertencentes às escolas de Educação Básica e demais instituições de Ensino Superior de dois estados do Brasil (Rio Grande do Sul e Santa Catarina). Sendo assim, foi enviado um questionário, de forma on-line, para os participantes de um curso de extensão e de disciplinas de graduação (pedagogia ou licenciaturas) ofertadas pelas pesquisadoras. Neste sentido, obteve-se três etapas de pesquisa, conforme apresentado a seguir.

Etapa 1 - Elaboração de um questionário para mapear o perfil do sujeito mobile: foi elaborado um questionário do tipo Survey que, de acordo com Gil (1999), trata-se de uma ferramenta que auxilia na obtenção de dados de maneira prática. Para isso, utilizouse como ferramenta o Google formulários. O questionário foi composto de 26 perguntas 
(incluindo a identificação e o termo de consentimento de livre esclarecimento) e foi elaborado por uma equipe multidisciplinar. Das questões que compõem o questionário, apenas duas são de resposta aberta, as demais são de múltiplas escolhas. Após isso, o questionário foi enviado para o público estratégico, neste caso para os docentes. O tempo de espera entre o envio e o recebimento das respostas foi de 15 dias.

Etapa 2: Aplicação do questionário: a coleta de dados foi realizada com a divulgação do questionário por meio da colaboração de escolas de Educação Básica e instituições de Ensino Superior, que enviaram o formulário aos professores. Para tanto, 1.138 professores o receberam, obtendo-se o retorno de apenas 28 participantes.

Etapa 3: Análise e discussão dos dados: Após a análise teórica e o retorno dos questionários, iniciou-se a tabulação e análise dos dados recebidos através do Survey. Para tanto, classificou-se em três categorias de análise, sendo elas: características do público respondente, uso dos dispositivos móveis no cotidiano e, por último, o uso educacional dos smartphones e tablets. Ademais, foram incluídas subcategorias, com o intuito de aprimorar à análise seguindo a proposta de Bardin $(1977$; 2011) para a compreensão dos dados. Na seção a seguir são apresentados os resultados e discussões que possibilitaram a identificação do perfil do professor mobile.

\section{RESULTADOS E DISCUSSÃO}

Esta seção aborda, a partir da coleta de dados, a identificação do perfil dos professores que utilizam os dispositivos móveis para fins educacionais. Sendo assim, houve a participação de professores da Educação Básica e do Ensino Superior. A seguir são apresentadas as particularidades do público-alvo desta pesquisa.

\subsection{CATEGORIA: CARACTERÍSTICAS DO SUJEITO}

Os participantes desta pesquisa representam um total de 28 docentes pertencentes a dois estados do Brasil, sendo eles Rio Grande do Sul e Santa Catarina. A idade variou entre 24 e 64 anos, sendo o maior número de participantes com 49 anos. Quanto ao gênero, verificou-se que $71 \%(n=20)$ respondentes se identificaram como sendo feminino e $29 \%(n=8)$ do masculino, conforme o gráfico 2.

Gráfico 2: Gênero dos participantes. 




Fonte: As autoras (2022).

Em relação ao nível de formação, observa-se que oito participantes responderam ter o curso de Pós-Graduação - Especialização completo $23 \%$ ( $n=8)$, seguido por $18 \%$ $(\mathrm{n}=6)$ respondents cursando Mestrado e $18 \%(\mathrm{n}=6)$ declararam que já possuem mestrado e doutorado por completo. Ainda destaca-se que 6\% $(n=2)$ dos participantes possuem graduação concluída e 3\% (n=1) está cursando o doutorado, de acordo com o gráfico 3. Nesta pergunta, obteve-se mais de uma resposta por respondente.

Gráfico 3: Nível de formação dos respondentes.

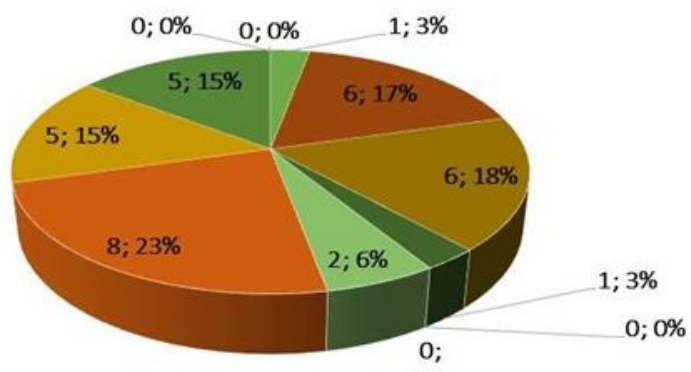

$0 \%$

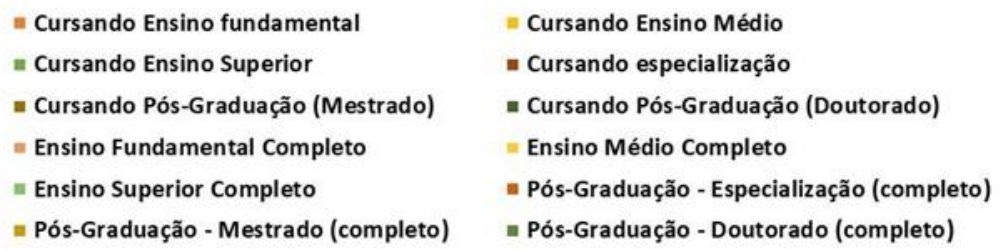

Fonte: As autoras (2022).

Desta forma, como pode ser observado, os professores respondentes deste estudo possuem formação mínima em nível superior para atuar tanto na Educação Básica quanto no Ensino Superior. Esses dados estão em concordância com o Plano Nacional de Educação (PNE) (2014-2021) em que, na META 16, destaca que deverá haver incentivo 
para formações docentes em nível de pós-graduação em $50 \%$ para os docentes da Educação Básica, até o último ano de vigência deste plano (BRASIL, 2021). Além disso, pretende-se incentivar que os professores realizem formação continuada em conformidade com a sua área de atuação, considerando as necessidades, demandas e contextualizações dos sistemas de ensino, público-alvo e realidade escolar.

Já em relação ao Ensino Superior, faz-se necessário formação em nível de pósgraduação, de acordo com o referido plano em vigência. Para tanto, a META 13 define que para obter qualidade da Educação Superior será necessário ampliar a proporção de mestres e doutores do corpo docente das instituições, chegando a $75 \%$, sendo que podese admitir um mínimo de 35\% de doutores (BRASIL, 2021). Acredita-se que os cursos de formação, seja inicial ou continuada, apresentam-se como possibilidade para a aquisição de novas aprendizagens e o compartilhamento de experiências e de informações, especialmente no que se refere ao uso das tecnologias educacionais. No próximo tópico, são abordados os dados referentes ao uso dos smartphones e tablets por parte dos respondentes, em relação às atividades que realizam com estes aparelhos seja de ordem pessoal, para entretenimento ou para comunicação.

\subsection{CATEGORIA: USO DOS DISPOSITIVOS MÓVEIS}

Nesta categoria aborda-se o uso dos dispositivos móveis de modo geral pelos professores, o que inclui seu uso no cotidiano, para atividades pessoais, entretenimento, comunicação e uso de redes sociais. Desse modo, indagou-se aos respondentes que tipo de aparelho eles possuíam. Para tanto, foram obtidos os seguintes dados, como pode ser visto no gráfico 4: 42\% $(n=16)$ dos sujeitos respondentes possuem smartphone, seguido de $32 \%(\mathrm{n}=12)$ que possuem tablets e smartphones, $13 \%(\mathrm{n}=5)$ participantes utilizam smartwatch, $10 \%(\mathrm{n}=4)$ indicaram fazer uso de notebook e $3 \%(\mathrm{n}=1)$ docente relatou manipular apenas o tablet.

Gráfico 4: Dispositivos mais utilizados pelos professores. 


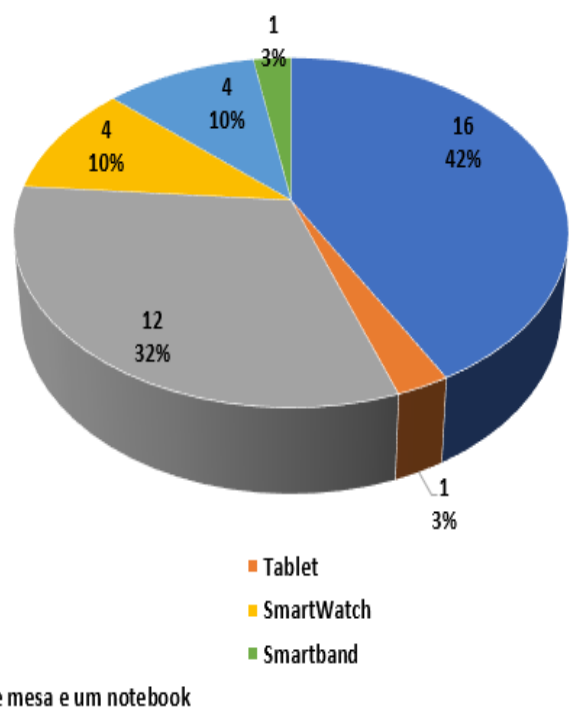

Fonte: As autoras (2022).

Com base no gráfico 4, compreende-se que os professores, em sua maioria, possuem pelo menos um DM. A partir disso, torna-se relevante considerar os tipos de atividades que podem ser produzidas a partir destes aparelhos com o objetivo de fomentar estratégias pedagógicas que contemplem tais dispositivos.

Ao serem questionados sobre a maneira como aprenderam a utilizar os DM, é possível observar, no gráfico 5 , que $89 \%(\mathrm{n}=25)$ professores indicaram que aprenderam a utilizar sozinhos os dispositivos, seguido de 3,6\% $(n=1)$ respondente, respectivamente, para cada uma das seguintes opções de aprendizagem em relação aos DM: com familiares, família e professores e todas alternativas anteriores.

Gráfico 5: Aprendizagem em relação ao uso dos dispositivos móveis. 


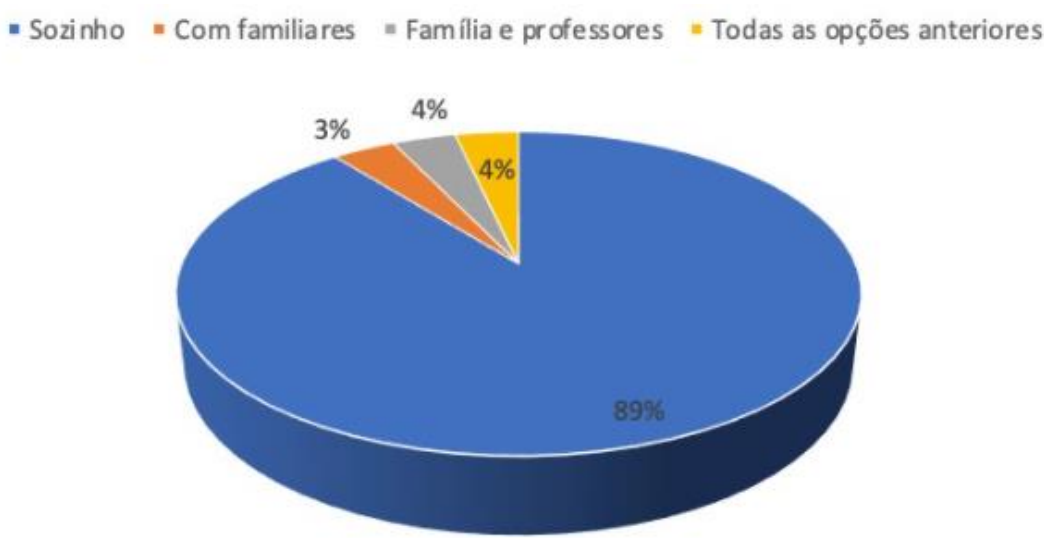

Fonte: As autoras (2022).

A partir dessas respostas, pode-se inferir que os docentes possuem características que corroboram com a sua autonomia. Nesse sentido, Castro Filho et al. (2016), destaca que os professores precisam aprimorar o seu desempenho em aprender algo novo de forma independente, a fim de obter condições para resolver problemas e estar aberto para novas possibilidades, como o uso dos dispositivos, por exemplo. Sendo assim, pode-se dizer que isso inclui o uso e domínio dos DM, tendo em vista que além de descobrir e aperfeiçoar as habilidades em relação aos aparelhos móveis, torna-se relevante que os docentes realizem cursos de formação contínua, como uma forma de refinar seus conhecimentos.

Quanto ao tempo destinado diariamente para o uso dos dispositivos móveis, a maioria dos professores, sendo $46 \%(\mathrm{n}=13)$ declarou que utiliza mais de cinco horas, $36 \%$ $(n=10)$ docentes relataram que utilizam entre três e cinco horas e 18\% $(n=5)$ afirmaram utilizar por até três horas ao dia. Desta forma, pode-se atribuir que o longo tempo de uso está relacionado às atividades docentes em canais virtuais, principalmente, em tempos de pandemia do COVID-19. Esses dados podem ser observados no gráfico 6.

Gráfico 6: Utilização diária dos dispositivos móveis (horas por dia). 




Fonte: As autoras (2022).

De acordo com o gráfico 6, percebe-se que esse registro, quanto às horas de uso dos DM por dia, pode estar atrelado às possibilidades de uso que estes equipamentos oferecem como rapidez, mobilidade, realização de várias atividades como ler e enviar emails, produzir conteúdo, fotos, vídeos e outros. Além disso, devido à pandemia do COVID-19 foram lançadas normativas sanitárias que determinaram o fechamento das escolas, universidades e demais locais de ensino em todo território nacional. Desse modo, os professores deram continuidade em seus planejamentos e aulas a partir de seus domicílios. Logo, utilizaram mais os DM para essa finalidade devido às suas potencialidades.

Quanto ao tempo em relação aos anos de uso dos dispositivos, observa-se que a maioria dos professores $89 \%(n=25)$ já utilizam os DM há mais de 6 anos. Nesta questão, o menor resultado apontado está entre os sujeitos que utilizam entre quatro e seis anos $11 \%(\mathrm{n}=3)$, conforme o gráfico 7 .

Gráfico 7: Anos de uso dos dispositivos móveis.

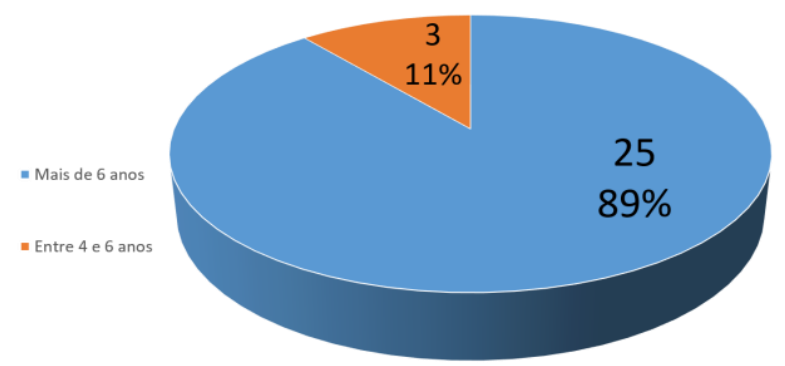

Fonte: As autoras (2022). 
Com base nas respostas do gráfico acima, pode-se verificar que os professores já manipulam esses aparelhos há algum tempo. Entretanto, não se pode afirmar que essa utilização é com fins educacionais ou para seu uso pessoal, como comunicação, pesquisas ou entretenimento. Mas, destaca-se que o fato de saberem utilizá-lo já amplia as possibilidades de inovação tanto no seu cotidiano, quanto no meio educacional. A seguir apresenta-se a subcategoria que está relacionada ao uso da internet através dos DM.

\subsubsection{USO DA INTERNET}

Nesta subcategoria apresenta o uso da internet através dos DM, uma ação cada vez mais recorrente entre os professores como meio de comunicação e aproximação entre sujeitos.

Em relação ao uso da internet, como mostra o gráfico 8, os docentes relataram que o tipo usado com maior frequência é a wi-fi, com $89 \%(\mathrm{n}=25)$ dos respondents. Para a opção com menor prevalência destaca-se as redes $3 \mathrm{~g}, 4 \mathrm{~g}, 5 \mathrm{~g}$ com conta pré-paga, perfazendo 4\% (n=1), já para a mesma opção de internet, porém com conta pós-paga, visualizou-se $7 \%(\mathrm{n}=2)$.

Gráfico 8: Tipo de internet utilizada com maior frequência.



Fonte: As autoras (2022).

Desta forma, compreende-se que o uso da internet wi-fi pode gerar maior estabilidade e velocidade durante a conexão, porém esse uso fica restrito a um domicílio ou outro lugar físico. Quanto às redes móveis, estas oferecem maior mobilidade, entretanto, em alguns casos, acontece a instabilidade ou até mesmo falta do sinal, o que pode prejudicar a utilização da internet através de um DM. Cabe destacar que estas 
possibilidades permitem a sua utilização em qualquer lugar e horário, desde que se tenha sinal e um aparelho apto para esta finalidade.

Ainda relacionado ao uso dos DM, questionou-se aos professores se eles sentiam dores em alguma parte do corpo após longos períodos de utilização dos dispositivos. Observa-se que 61\%, $(n=17)$ respondentes, afirmaram apresentar dores na parte superior do corpo após o uso destes aparelhos. Por outro lado, 32\% (n=9) declararam que não sentem nenhum sintoma. Enquanto a menor prevalência dos sujeitos composto por $7 \%$ $(n=2)$, relataram ter dores em partes diferentes do corpo, conforme gráfico 9.

Gráfico 9: Dores no corpo devido ao uso dos dispositivos móveis.

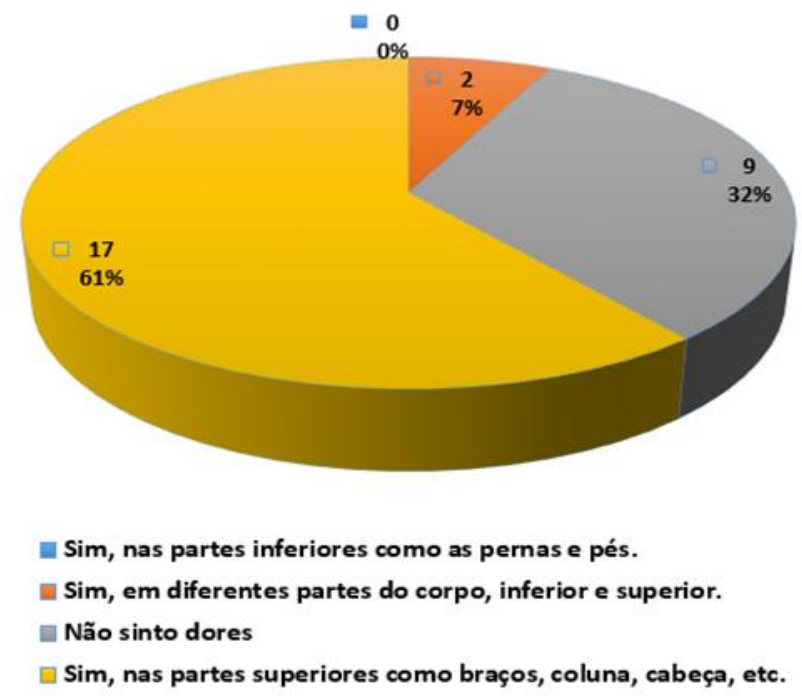

Fonte: As autoras (2022).

Assim sendo, pode-se considerar, de maneira especulativa, que devido às condições laborais que os docentes encontram-se na atualidade, as dores podem estar relacionadas a falta de orientação ergonômica. Além disso, torna-se necessário que esse profissional tenha um acompanhamento durante suas atividades de forma que venha utilizar de maneira adequada os recursos tecnológicos, mantendo uma postura adequada. Sabe-se que estas considerações, são apenas recomendações, pois na prática do dia a dia os docentes e demais trabalhadores acabam muitas vezes deixando de lado estas indicações. Como consequência, no final do expediente, sentem os sintomas decorrentes do uso inadequado dos DM.

Ao questionar aos docentes qual a atividade realizada com maior frequência quando do uso dos dispositivos móveis, a opção de assistir aulas, gravar vídeos, produzir 
materiais e/ou estudar foi a mais selecionada pelos participantes, perfazendo $37,7 \%$ $(n=10)$ respostas. O acesso às redes sociais fez parte de $25 \%(n=7)$ respondentes. No entanto, a ação de conversar com os amigos e familiares foi a terceira alternativa mais lembrada pelos professores, sendo escolhida por $14,3 \%(n=4)$ dos docentes. As demais opções obtiveram um índice de 3,6\%, $(\mathrm{n}=1)$ participante em cada possibilidade expressa, conforme demonstra o gráfico 10.

Gráfico 10: Atividade realizada com maior frequência quando do uso de DM com internet.

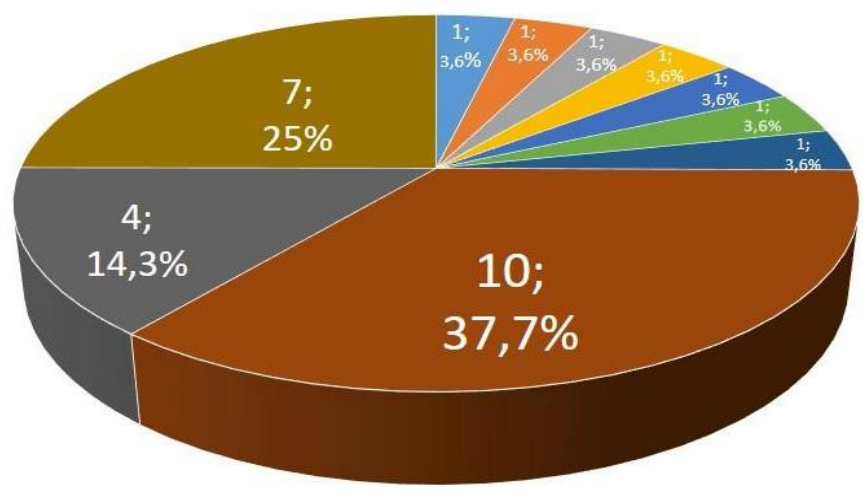

- Pesquisar materiais para estudo

- Trabalhar

- Assistir vídeos e jogar

- Via de comunicação entre mim, alunos e professores

- Estudar e lecionar, como professora

- Trabalhar. Sou professora

- Planejar e organizar diversas atividades sociais e profissionais

- Assistir aulas, gravar vídeos, produzir materiais e/ou estudar

- Conversar com amigos e familiares

- Acessar redes sociais

Fonte: As autoras (2022).

Com base no gráfico 10, pode-se averiguar que os professores utilizam na sua maioria os DM conectados na internet para assistir aulas, gravar vídeos, produzir materiais e/ou estudar. Esses dados demonstram que os dispositivos são capazes de auxiliar nas atividades de trabalho, inclusive de caráter educacional. Essa constatação vai ao encontro de Sonego (2019), em que aponta que os DM podem auxiliar no desenvolvimento da sua autonomia e do processo de ensino e aprendizagem, explorando suas características de mobilidade, portabilidade e conectividade. Além disso, estes dispositivos oferecem distintas possibilidades para permitir acesso às redes sociais e manter a comunicação com outras pessoas. Nesta perspectiva, a seguir é apresentada a subcategoria uso das redes sociais por docentes.

\subsubsection{USO DAS REDES SOCIAIS}

Nesta subcategoria, elucida-se como acontece o uso dos DM para acessar as redes sociais por parte dos professores. Para tanto, mostra-se o gráfico 11, em que aponta um 
número maior de acessos ao WhatsApp, com 96,4\%, $(\mathrm{n}=27)$ docentes utilizam esta como rede preferida, seguido do Youtube 64,3\% (n=18) respondentes, Facebook com 57,1\%, $(\mathrm{n}=16)$ e o Instagram com 42,9\% ( $\mathrm{n}=12)$ participantes da pesquisa. Ainda destaca-se que o Twitch e o Snapchat não foram selecionados como redes sociais de maior frequência de utilização.

Gráfico 11: Redes sociais mais utilizadas.

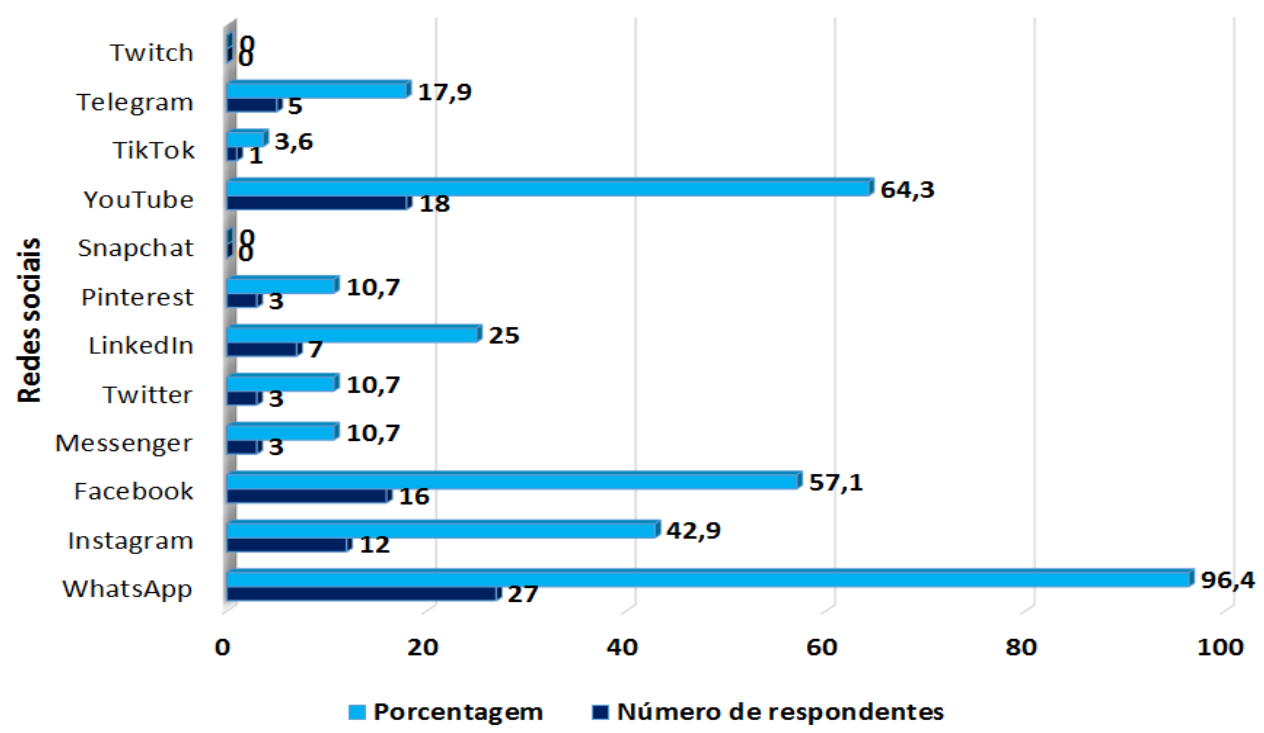

Fonte: As autoras (2022).

Conforme o gráfico acima, pode-se ver as redes sociais mais utilizadas pelos professores. O WhatsApp é uma opção presente no dia a dia de muitos sujeitos, pois permite criar uma ampla teia de comunicação, seja para trabalho, estudo ou para ampliar as formas de conversação. Além disso, cria possibilidades para divulgação de conteúdo, a livre expressão e o compartilhamento de informações, atividades essas que também são viáveis através do Facebook, YouTube e Instagram.

Diante deste cenário, questionou-se aos participantes da pesquisa qual era a rede social preferida deles. Sendo assim, os motivos explicitados pelos docentes foram em relação ao compartilhamento de conteúdo $25 \%(n=7)$ sete respondentes. Na sequência, $21,4 \%(n=6)$ indicaram acessar para informar-se sobre as notícias do Brasil e do mundo e para conversar com os amigos 17,9\% $(n=5)$ apontaram essa alternativa. As justificativas de diversão e estudo também foram escolhidas pelos sujeitos da pesquisa, com 10,7\% $(n=3)$ e $7,1 \%(n=2)$ das respostas, respectivamente. 
Gráfico 12: Motivos da utilização das redes sociais preferidas.

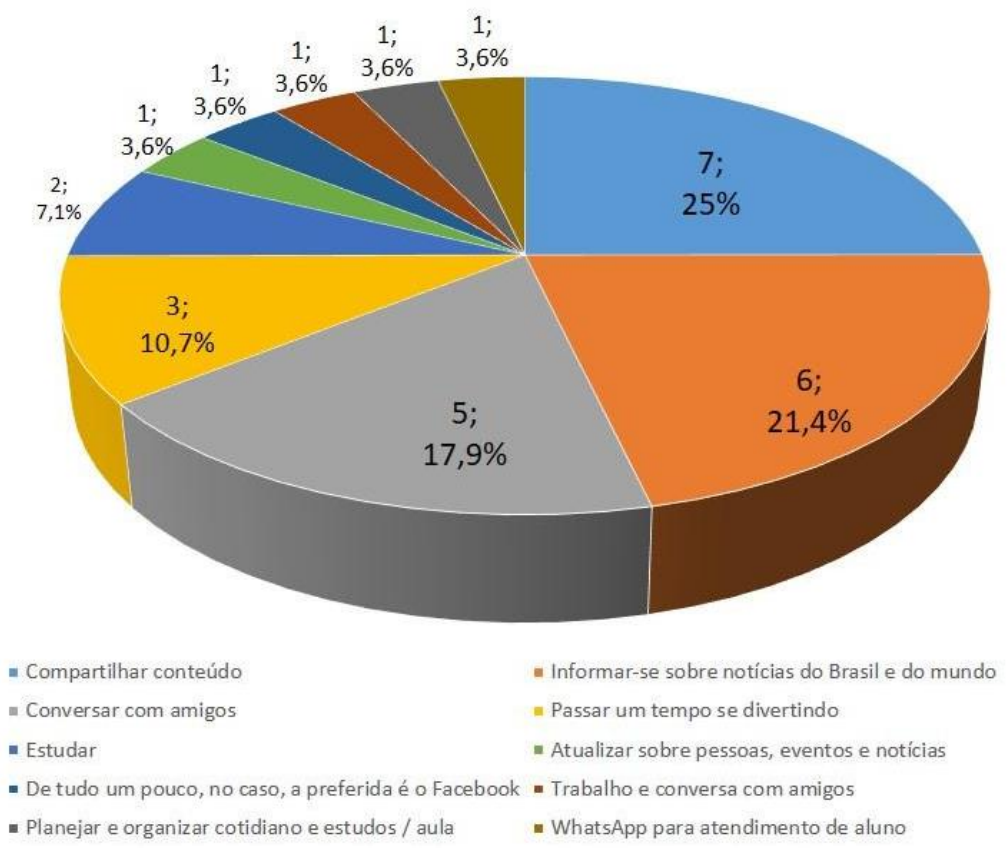

Fonte: As autoras (2022).

Desse modo, averigua-se que as redes sociais mais utilizadas estão em consonância com o compartilhamento de conteúdo que pode ser de ordem pessoal, trabalho e educacional. Além disso, nota-se que os respondentes estão atentos às notícias do Brasil e do mundo, bem como gostam de acessar redes que permitem conversar com os amigos e familiares. Para tanto, torna-se uma alternativa para manter o contato e aproximar pessoas através dos DM. Na sequência, são abordadas atividades que os docentes realizam com os dispositivos móveis.

\subsubsection{ATIVIDADES COM OS DISPOSITIVOS MÓVEIS}

Nesta subcategoria são elencadas as atividades realizadas com maior frequência pelos professores por meio dos dispositivos móveis. Desta forma, através do gráfico 13, pode-se perceber que $67,9 \%(\mathrm{~N}=19)$ dos respondentes enviam e leem e-mail. Outros $60,7 \%(n=17)$ pesquisam diferentes fontes sobre um tópico específico de seu interesse e $46,4 \%(n=13)$ docentes realizam leituras ou assistem notícias on-line. As ações menos selecionadas foram consultar um dicionário ou enciclopédia on-line, jogar on-line sozinho ou com outras pessoas, conversar, planejar o cotidiano com os familiares e 
participar de reuniões/dar aulas virtuais, cada uma perfazendo 3,6\% $(n=1)$ das respostas, respectivamente.

Gráfico 13: Atividades realizadas com maior frequência (múltipla escolha).

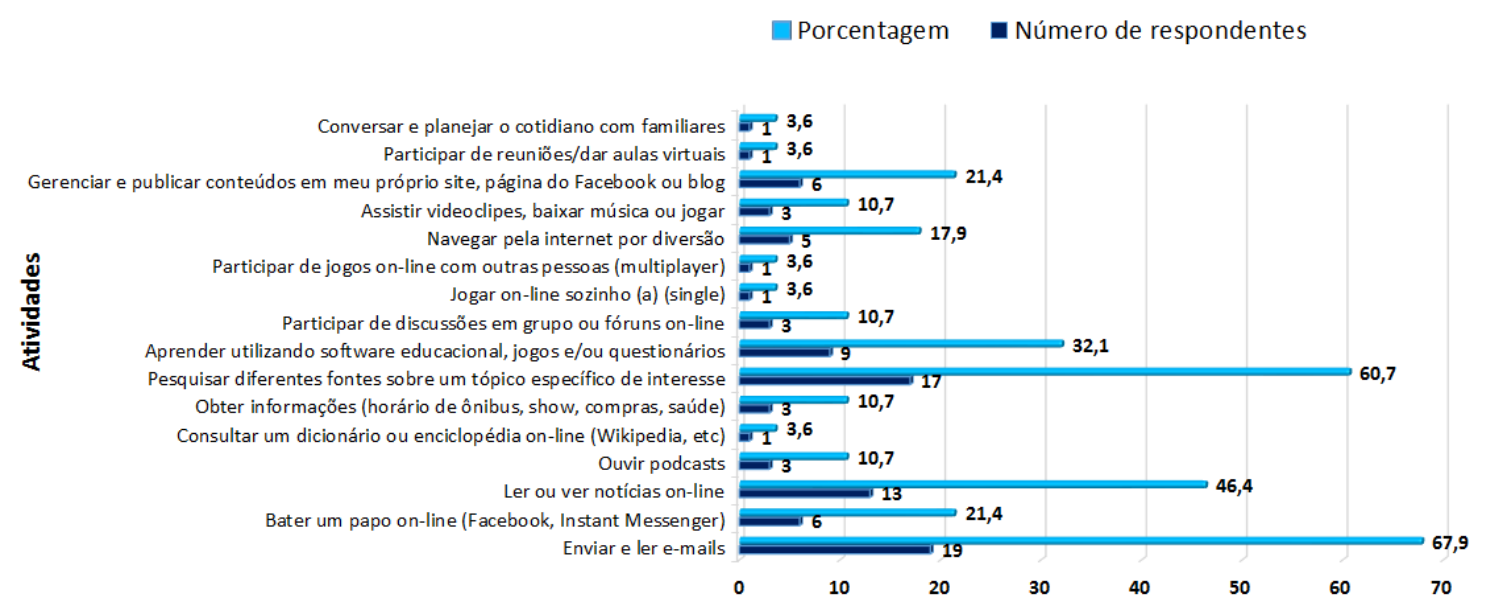

Fonte: As autoras (2022).

Quanto aos indicadores do gráfico acima, visualiza-se que são distintas as atividades realizadas pelos participantes da pesquisa, em função do seu contexto, realidade, dia a dia, demandas e tarefas a serem realizadas através dos dispositivos móveis.

Ainda, perguntou-se aos docentes quais os materiais que compartilhavam com maior frequência através dos DM, o gráfico 14 aponta as seguintes respostas: 50\% $(n=14)$ respondentes indicaram textos, outros $46,4 \%(n=13)$ apontaram os arquivos como apresentações, texto em word ou pdf, 42,9\% (n=12) professores relataram que compartilham vídeos, seguidos de $35,7 \%(n=10)$ respondentes que enviam fotos. 
Gráfico 14: Materiais compartilhados com maior frequência (múltipla escolha).



Fonte: As autoras (2022).

Desse modo, observa-se que as atividades realizadas pelos docentes são variadas e estão de acordo com a docência e com a vida pessoal. Sendo assim, nota-se que eles realizam estas ações com frequência, o que demonstra o domínio sob o uso dos dispositivos móveis, explorando seus aplicativos e ferramentas disponíveis para nos auxiliar na execução de tarefas.

Entre as ações executadas com o dispositivo móvel, 57,1\% (n=16) dos docentes citaram que exercem com maior frequência o compartilhamento de fotos pessoais. Outros $53,6 \%$ respondentes $(n=15)$ indicaram a permissão de acesso à câmera de seu dispositivo e 39,3\% professores $(n=11)$ declararam que fazem o compartilhamento de sua localização geográfica. Por outro lado, a única opção não selecionada por nenhum sujeito da pesquisa foi o compartilhamento de senhas, o qual denota uma preocupação com a segurança digital, como indica o gráfico 15. 
Gráfico 15: Ações realizadas com o dispositivo móvel (múltipla escolha).

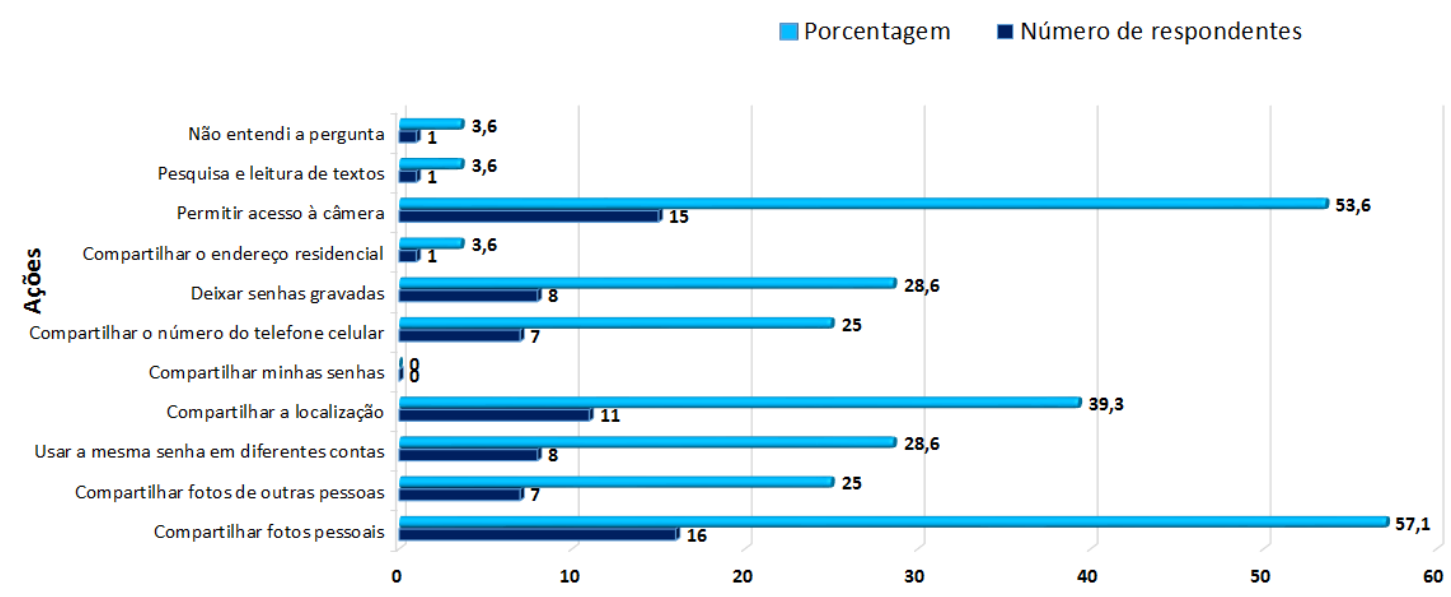

Fonte: As autoras (2022).

Nesta questão percebe-se que os docentes possuem conhecimentos quanto a funcionalidades que os DM e o uso da internet oferecem, principalmente, em questões de segurança digital. Portanto, as ações realizadas por eles estão de acordo com suas necessidades e preferências, dentro do contexto e da realidade de cada um. Na sequência, é abordada à última categoria deste estudo, em que aponta-se as características que compõem um sujeito mobile, nesse caso, o professor.

\subsection{CATEGORIA: MAPEAMENTO DO SUJEITO MOBILE}

Esta categoria visa apresentar peculiaridades do sujeito mobile que foram pesquisadas através de um mapeamento. Dessa forma, pretende-se demonstrar por meio das subcategorias e gráficos como se dá o uso educacional dos DM pelos docentes. A seguir aponta-se o uso dos dispositivos no âmbito da educação.

\subsubsection{O USO DOS DISPOSITIVOS MÓVEIS PARA ATIVIDADES EDUCACIONAIS}

Esta subcategoria está associada ao uso dos DM para a realização de tarefas de estudo. Logo, é necessário refletir sobre a realidade atual referente a inserção das tecnologias digitais em rede, especialmente, sobre os dispositivos móveis. Desse modo, verifica-se que essa inclusão digital está de acordo com as propostas articuladas pela Base Nacional Comum Curricular (BNCC). Portanto, torna-se relevante identificar como pode acontecer esse uso por parte dos professores para que as formas de ensino e aprendizagem sejam ampliadas e fortalecidas. 
Ao perguntar aos participantes quanto tempo faz que eles já utilizam smartphones ou tablets com a finalidade educacional. Conforme o gráfico 16, observa-se que $39,3 \%$ participantes $(n=11)$ já utilizam os DM há mais de 6 anos, 28,6\% respondentes $(n=8)$ fazem uso destes entre 1 a 3 anos, $25 \%(n=7)$ entre 4 a 6 anos e 7,1\% pessoas $(n=2)$ utilizam a menos de um ano.

Gráfico 16: Tempo de utilização do dispositivo móvel para atividades educacionais.

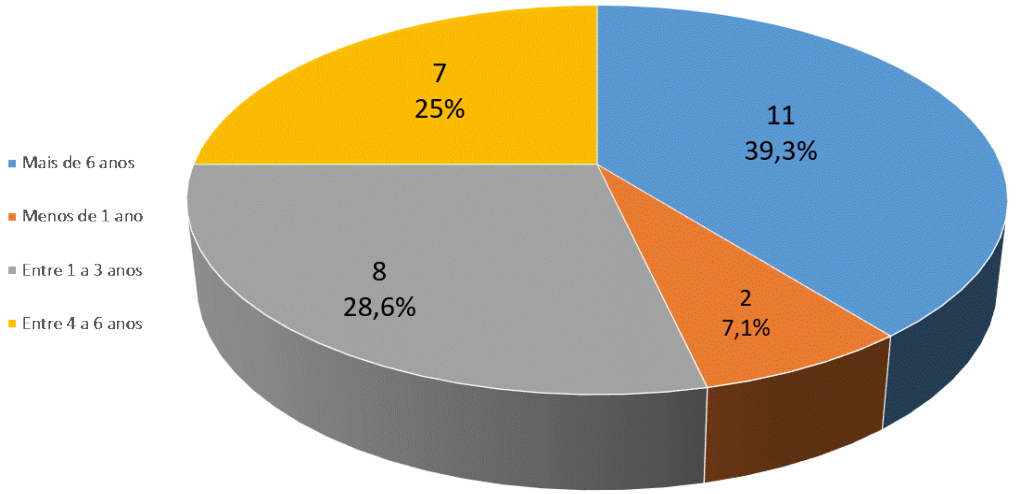

Fonte: As autoras (2022).

Esses dados expressos no gráfico acima, indicam que cada vez mais as pessoas estão aderindo o uso dos DM como um recurso que permite realizar várias atividades tanto na vida pessoal, quanto no trabalho e na educação. Logo, acredita-se que estes aparelhos oferecem condições para executar tarefas com objetivos educacionais e cada vez mais os docentes estão aderindo a este uso.

Ao serem questionados sobre qual atividade educacional era realizada com maior frequência pelos participantes, observou-se no gráfico 17 que, $71,4 \%$ participantes $(n=20)$ afirmaram utilizar para pesquisar informações ou materiais, o mesmo índice de resposta $(71,4 \%)$ foi identificado para conversas com professores e colegas por aplicativos como Instagram, Telegram, Whatsapp e Facebook. Já 67,9\% professores $(\mathrm{n}=19)$ indicaram usar os dispositivos para ingressar em ambientes virtuais de aprendizagem. Entretanto, foram identificadas outras atividade como acesso ao YouTube e a plataforma Meet, com índices de $7,1 \%(n=2)$ e $3,6 \%(n=1)$ respondentes nesta pesquisa, respectivamente. 
Gráfico 17: Atividades educacionais realizadas com maior frequência. (múltipla escolha).

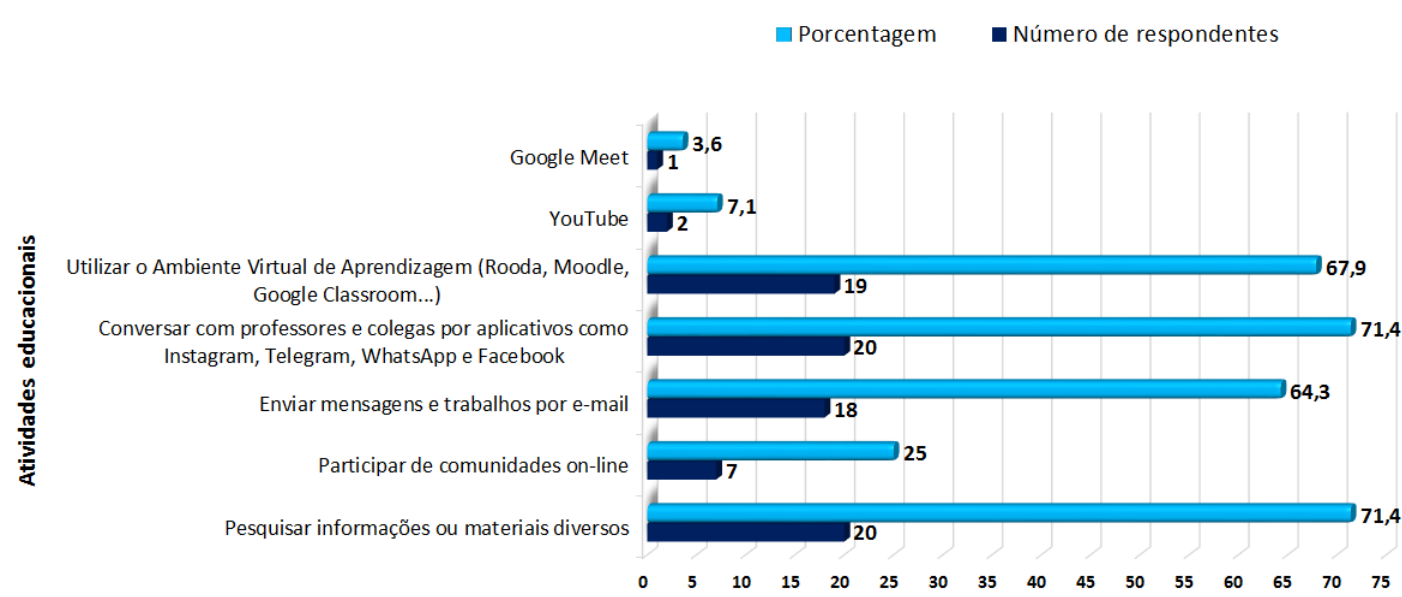

Fonte: As autoras (2022).

Considera-se que estes percentuais estão relacionados com o atual momento da educação do Brasil que, por motivos da pandemia de COVID-19, as atividades escolares estão sendo realizadas na modalidade de Ensino Remoto Emergencial. Por consequência, as tarefas estão sendo executadas em grande parte através dos dispositivos móveis.

Sobre quais atividades os participantes sabem fazer com o seu respectivo DM, $100 \%(\mathrm{n}=28)$ disseram saber enviar um arquivo por e-mail, 92,9\% $(\mathrm{n}=26)$ apontam que dominam tanto responder um questionário quanto tirar fotos. Na sequência, $85,7 \%$ ( $\mathrm{n}=24)$ declaram conseguir responder publicações nas redes sociais, $82,1 \%(n=23)$ dizem que sabem instalar novos aplicativos e 71,4\% $(n=20)$ relataram saber participar de um fórum de discussão, usar a maioria dos recursos de um DM e até modificar um texto. Ainda são vistos outras ações conforme mostra o gráfico 18. 
Gráfico 18: Atividades que sabe fazer com o dispositivo móvel (múltipla escolha).

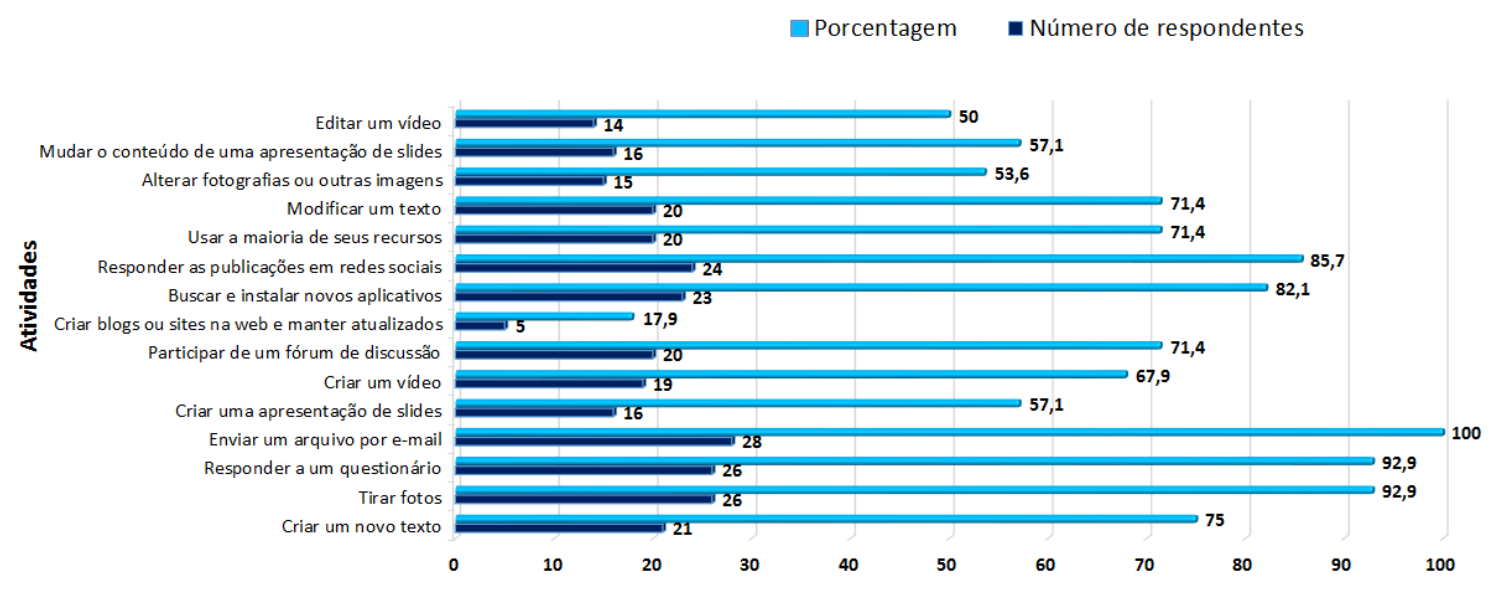

Fonte: As autoras (2022).

Portanto, consideram-se diversas as atividades que os docentes realizam com maior frequência. Dessa forma, este domínio quanto à utilização dos recursos disponíveis nos DM contribuem para o planejamento e implementação de atividades de estudo, que podem ser elaboradas através destas funcionalidades. Diante deste contexto, é relevante conhecer sobre a proteção dos dados na internet, um tema importante quando feito o uso e o compartilhamento de dados em rede.

\subsubsection{PROTEÇÃO DOS DADOS NA INTERNET}

A proteção dos dados na internet é um assunto que merece atenção e cuidado, pois a exposição dos dados de forma incorreta, pode gerar incômodos e até mesmo a exibição de conteúdo sem a devida autorização do seu proprietário. Nesse sentido, observou-se ao perguntar (gráfico 19) sobre qual(is) ação(ões) os docentes sabem realizar para proteger seus dados na internet. Assim, obteve-se um índice de 89,3\% $(n=25)$ que responderam que cuidam da sua privacidade evitando repassar informações pessoais, 85,7\% $(n=24)$ dizem que cuidam da sua privacidade evitando repassar informações pessoais alheias e conteúdos que possam causar constrangimento. 
Gráfico 19: Ações que sabe realizar para proteger os dados pessoais na internet (múltipla escolha).

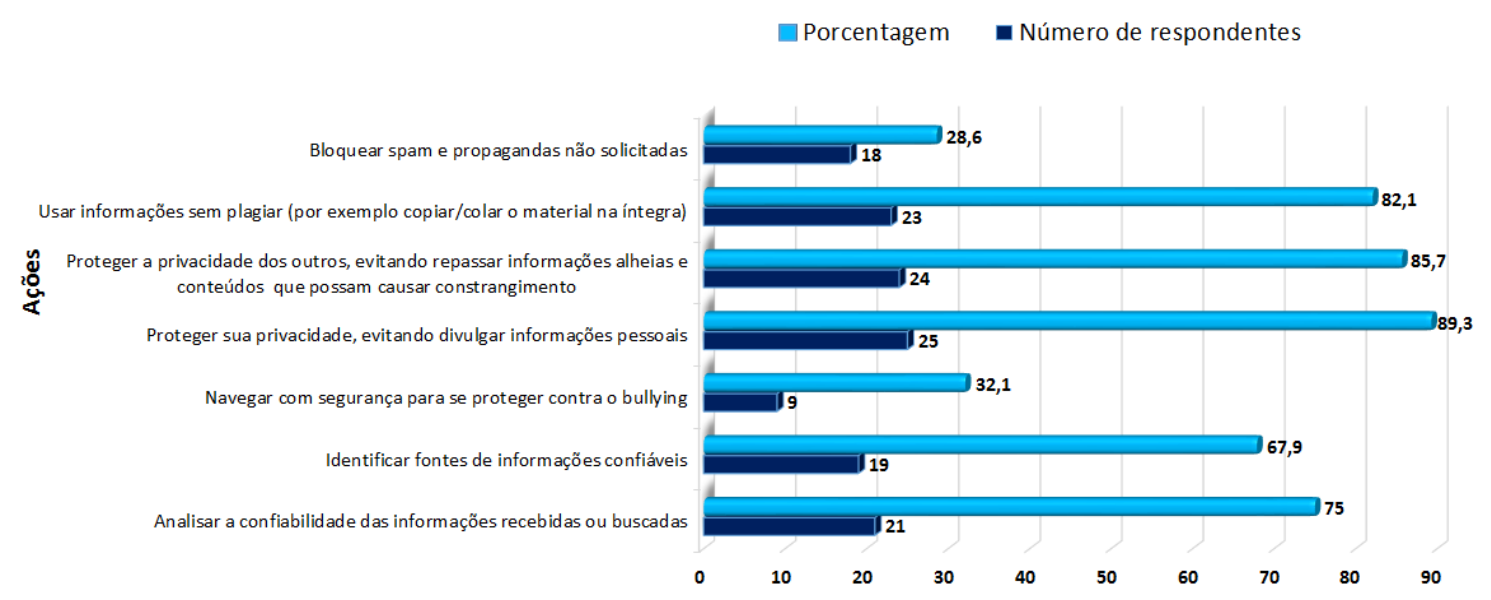

Fonte: As autoras (2022).

Desse modo, percebe-se que os participantes conhecem os riscos em relação à exposição de dados pessoais na internet. Contudo, acredita-se que somente o fato de reconhecer as ameaças não é suficiente para a proteção dos dados. É notório que além disso, deve-se evitar ações que possam deixar senhas, fotos, conteúdos e outras informações vulneráveis na rede. Destaca-se que é relevante que o docente tenha uma atitude cautelosa ao acessar sites desconhecidos, que possam apropriar-se dos dados registrados no seu dispositivo móvel.

Os participantes da pesquisa também apontaram o principal benefício do uso de dispositivos móveis para fins educacionais, no qual obteve-se como a maior porcentagem $67 \%(\mathrm{n}=19)$ a opção de acessar conteúdo em qualquer lugar e horário, desde que tenha acesso à internet. Em segundo, aponta-se que 25\% dos respondentes $(\mathrm{n}=7)$ afirmaram que o benefício seria o fato de ter mais independência para realizar as atividades e descobrir novos assuntos do seu interesse. Na sequência, 10,7\% professores $(n=3)$ apontaram que consideram o fato de poder dedicar mais tempo aos estudos e trabalho devido à mobilidade que o dispositivo oferece. Por fim, apenas 3,6\% responderam $(n=1)$ destacou que percebe como privilégio em relação ao uso dos DM, a possibilidade de poder usar este aparelho simultaneamente com o computador, recebendo links, mensagens, enviando fotos e e-mail. Estes dados encontram-se apresentados no gráfico 20.

Gráfico 20: Principal benefício do uso de um dispositivo para fins educacionais. 


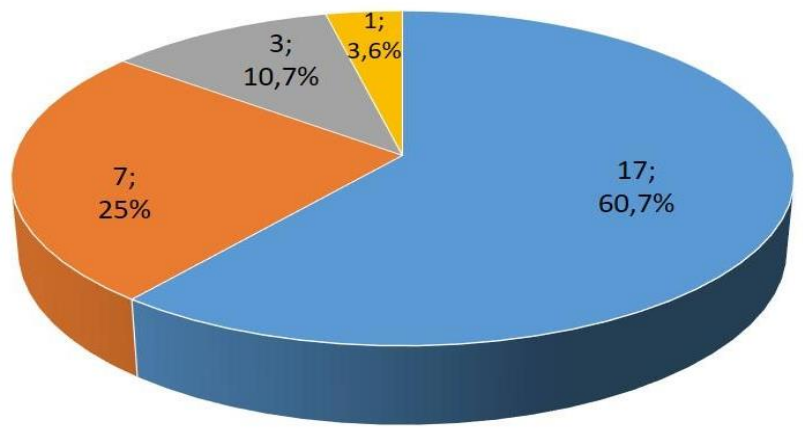

- Acessar o conteúdo em qualquer local e horário, desde que tenha acesso a internet

- Ter maior independência para realizar as atividades e descobrir sobre mais assuntos do meu interesse

- Dedicar mais tempo aos estudos, devido a mobilidade do dispositivo

- Auxiliar no uso do computador recebendo links mensagens e enviando fotos em emails para o computador

Fonte: As autoras (2022).

Dessa forma, de acordo com o gráfico 20, considera-se que os benefícios indicados pelos professores em relação ao uso dos DM estão associados aos fins educacionais. Como visto, são várias possibilidades e, de acordo com Reinoso e Tavares (2015), estas devem estar em consonância com o objetivo de viabilizar e agilizar a execução de atividades pedagógicas.

Ainda na perspectiva envolvendo o uso dos dispositivos móveis com finalidade educacional, pode-se observar que $32,1 \%$ professores $(n=9)$ afirmaram que propõem atividades para os seus alunos participarem através dos DM. O mesmo percentual foi verificado pelos respondentes que indicaram que não utilizam os smartphones e tablets em suas práticas pedagógicas. No entanto, $28,6 \%$ docentes $(n=8)$ destacaram que utilizam estes aparelhos tanto para construir conteúdos para os alunos como atividades, quanto para comunicar-se com esse público. Por fim, 3,6\% $(n=1)$ afirmou que faz uso dos dispositivos móveis somente para criar conteúdo das suas aulas, mas não referiu-se ao compartilhamento.

Gráfico 21: Desenvolvimento de práticas pedagógicas envolvendo o uso de dispositivos móveis em sala de aula. 


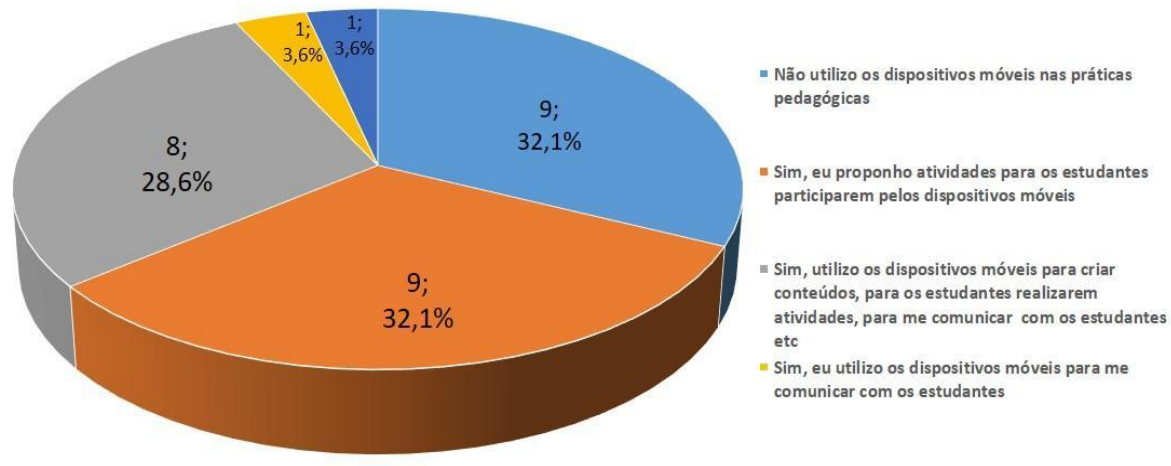

Fonte: As autoras (2022).

Diante deste contexto, ainda investigou-se como os docentes utilizam os dispositivos móveis em sala de aula. Desse modo, verificou-se as seguintes situações utilizando os DM: "encaminho atividades para que os alunos realizem"; "por exemplo, atividades como quiz interativo (on-line), criação de mural interativo"; "toda ferramenta tecnológica utilizada como metodologia ativa envolve o uso do smartphone"; "para trabalhar com nuvens de palavras"; "propondo e sugerindo jogos, enviando atividades por e-mail e propondo momentos em sala de aula"; "eu utilizo o dispositivo móvel para acessar uma ferramenta digital como o canva, uma ferramenta que o aluno pode utilizar para criar várias apresentações com textos e imagens"; "eu crio um link ativo de um arquivo em PDF. Neste arquivo PDF eu reúno todo o conteúdo de uma quinzena do currículo. Aqui em Santa Catarina, no ano de 2021, o período escolar é de ensino híbrido. Trata-se de uma semana de aula na escola e uma semana de atividades remotas. Para os alunos este arquivo PDF serve como um guia de estudos digital. Neste arquivo reúno os vídeos que eles devem assistir, o conteúdo das aulas (presenciais e remotas) e os exercícios do período (servindo como avaliação e medição da frequência). Este arquivo PDF, por ser um link ativo, pode ser distribuído por whatsapp, Google classroom, e-mail e qualquer rede social"; "numa das escolas, temos grupos de whatsapp das turminhas e postamos ali as atividades. Então, atendemos os alunos por essa rede”.

Portanto, entende-se que os professores já possuem o hábito de utilizar os DM para fins educativos, seja para pesquisar, enviar atividades e conteúdo para os alunos, uso de plataformas e como uma ferramenta para comunicação. Sendo assim, percebe-se que já existe um certo domínio de uso dos smartphones e tablets por parte dos docentes, 
fazendo com que eles explorem suas funcionalidades e incorpore-as nas atividades escolares. Essas ações destacadas pelos participantes contribuem para identificar os profissionais que possuem um perfil diferenciado em relação ao uso dos dispositivos móveis. Nesse sentido, deve-se levar em consideração que eles executam tarefas tanto do dia a dia, de entretenimento, comunicação, quanto educacionais. Desta forma, podem diversificar e inovar as suas práticas e também atender demandas contemporâneas e estudantis, visto que seus alunos muitas vezes são oriundos de uma geração conectada.

Por fim, solicitou-se aos participantes da pesquisa que manifestassem suas observações (sugestões/comentários) que julgarem pertinentes a serem destacadas a respeito da investigação e do uso dos dispositivos móveis. A figura 1 abaixo representa estes registros. 
Figura 1: Registro dos professores.

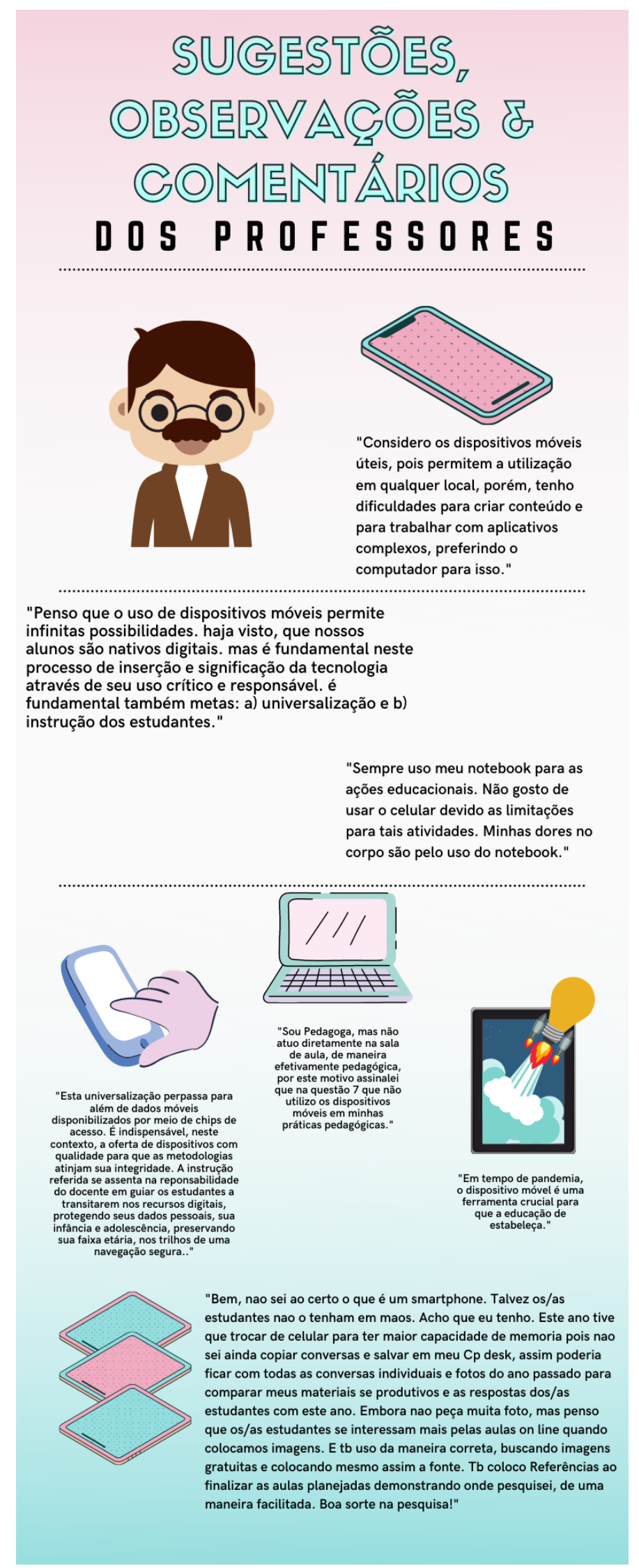

Fonte: As autoras (2022). 
Conforme a figura 1, observou-se que, embora muitos dos respondentes já façam uso dos DM, ainda existe um índice que tem receio em utilizá-lo ou acredita ser um desafio na sua atuação docente. Desta forma, não se pode generalizar que os smartphones e tablets estão inseridos nas práticas educacionais, embora essa situação não signifique que estão incorporados nas atividades educacionais esses recursos, conforme a figura 2 aponta.

Figura 2: Características que compõem o perfil do professor mobile

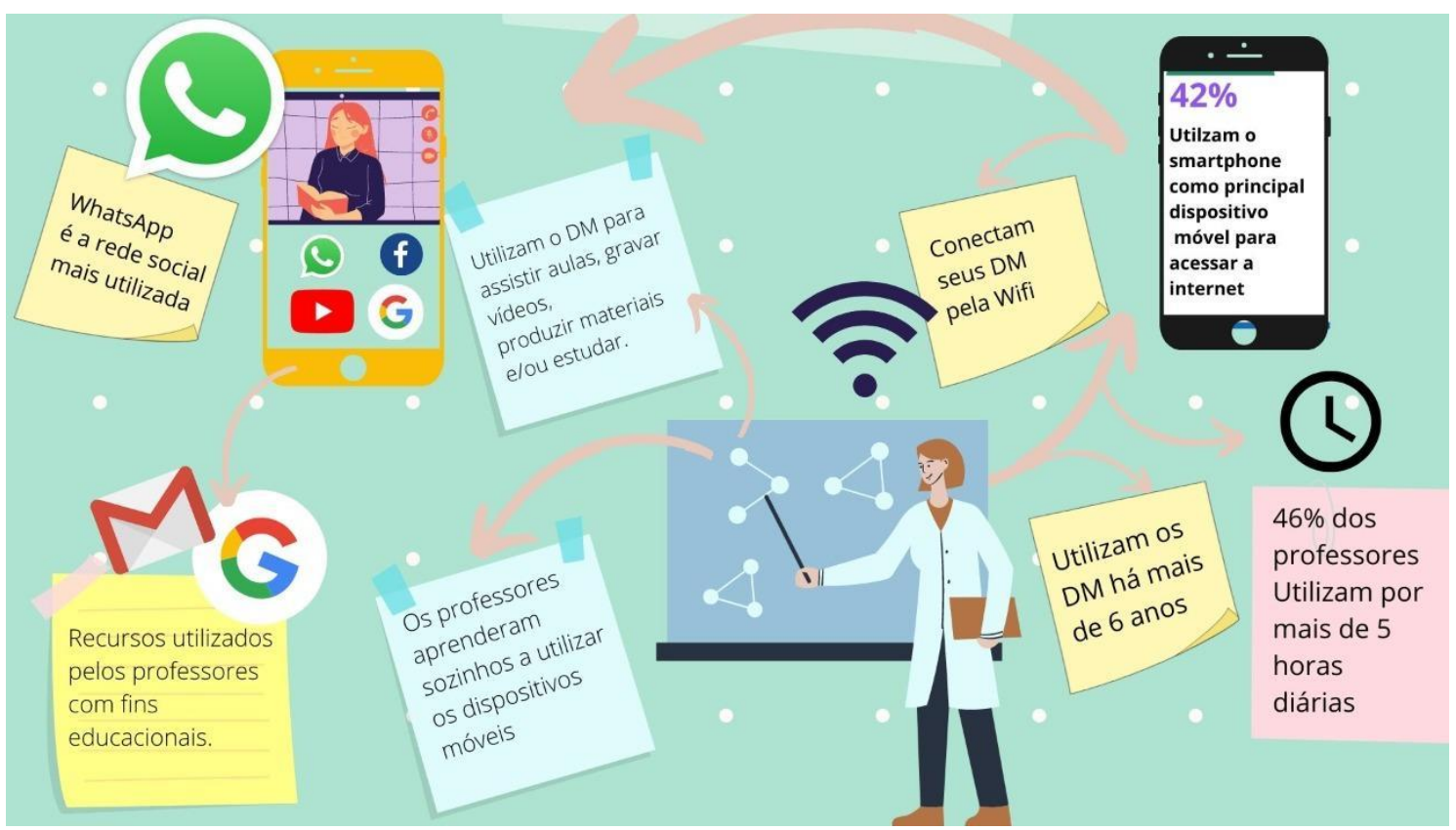

Fonte: As autoras (2022).

Com base na figura 2, observa-se que os dados coletados e sua análise apontam um público que possui familiaridade com estes aparelhos, fazendo uso dos mesmos há pelo menos seis anos. Dessa forma, pode contribuir com os professores quanto à exploração dos smartphones, tablets e o planejamento de atividades a partir dos recursos, funcionalidades disponíveis nos dispositivos e, consequentemente, sua implementação com os estudantes.

\section{CONSIDERAÇÕES}

O objetivo desta pesquisa foi identificar as características que compõem o perfil do professor mobile, verificando suas potencialidades e fragilidades em relação ao uso de DM na docência. No decorrer do estudo foi possível perceber que o consumo de informações ainda é uma das principais atividades realizadas, seja a pesquisa de materiais, 
de conteúdo, informações, notícias e, posteriormente, o seu compartilhamento com outros sujeitos. Estas ações colaboram para ultrapassar as dificuldades em relação aos DM e criar possibilidades para a realização de atividades com fins educacionais. A utilização das tecnologias digitais no processo de ensino e aprendizagem, ainda apresenta-se como um grande desafio para muitos docentes. Entretanto, de acordo com os resultados elucidados, percebe-se que os professores estão superando as barreiras e criando um novo no cenário educacional. Desta forma, podem vislumbrar os smartphones e tablets como uma perspectiva pedagógica e inovadora, tanto para os estudantes quanto para os docentes. Por fim, acredita-se que este mapeamento, não finda por aqui, deve ser aprimorado conforme as demandas de uso dos DM acerca deste perfil mobile, especificamente, do professor e sua relação com os dispositivos móveis.

\section{REFERÊNCIAS}

BARDIN, L. Análise de Conteúdo. Lisboa: Edições 70, 1977.

BARDIN, L. Análise de Conteúdo. Tradução de Luís Antero Reto e Augusto Pinheiro. São Paulo: Edições 70, 2011.

BRASIL, MINISTÉRIO DA EDUCAÇÃO E CULTURA. Plano Nacional de Educação. Disponível em: http://pne.mec.gov.br/. Acesso em: 04 de junho de 2021.

CASTRO FILHO, J. A. D.; FREIRE, R. S.; MAIA, D. L. (2016). Formação docente na era da cibercultura. Revista Tecnologias na Educação, 16(8), p. 1-21. Disponível em: https://repositorio.ufrn.br/handle/123456789/21449. Acesso em: 03 de maio de 2021.

CETIC.BR. (2021). Pesquisa web sobre o uso da Internet no Brasil durante a pandemia do novo coronavírus: Painel TIC COVID-19. Disponível em: https://cetic.br/pt/publicacao/painel-tic-covid-19/. Acesso em: 28 de abril de 2021.

CGI.BR. Celular é o dispositivo mais utilizado por usuários de Internet das classes DE para ensino remoto e tele trabalho, revela o Painel TIC COVID-19. Disponível em: https://www.cgi.br/noticia/releases/celular-e-o-dispositivo-mais-utilizado-porusuarios-de-internet-das-classes-de-para-ensino-remoto-e-teletrabalho-revela-painel-ticcovid-19/. Acesso em: 06 de novembro de 2020.

CRUB. MEC publica a Portaria 395/20 e prorroga as aulas remotas no sistema federal de Ensino Superior. Disponível em: http://www.crub.org.br/blog/mec-publicaa-portaria-39520-e-prorroga-as-aulas-remotas-no-sistema-federal-de-ensino-superior/. Acesso em: 03 de junho de 2020.

GIL, A. C. Métodos e técnicas de pesquisa social. $5^{a}$ edição. São Paulo: Atlas, 1999. 
KRIMBERG, L. AppEduMobile: Parâmetros para a construção de aplicativos educacionais com foco no Sujeito Mobile. 2019. 178p. (Dissertação de mestrado, UFRGS, Porto Alegre). Disponível em: https://lume.ufrgs.br/handle/10183/200081. Acesso em: 23 de maio de 2021.

REINOSO, L. F.; TAVARES, O. L. MVLIBRAS: ambiente digital para comunidades de aprendizagem com recursos inclusivos para surdos. In: XXVI Simpósio Brasileiro de Informática na Educação. Maceió: Alagoas/Brasil: 2015, p.772-781.

SONEGO, A. H. S. ARQPED-MOBILE: Uma arquitetura pedagógica com foco na aprendizagem móvel. 2019. 241p. (Tese de doutorado, UFRGS, Porto Alegre).

Disponível em: https://www.lume.ufrgs.br/handle/10183/197443. Acesso em: 21 de maio de 2021.

UNESCO. TIC na educação do Brasil. Disponível em:

https://pt.unesco.org/fieldoffice/brasilia/expertise/ict-education-brazil. Acesso em: 04 de setembro de 2021.

VIDAL, A. S.; MIGUEL. J. R. As Tecnologias Digitais na Educação Contemporânea. Id on Line. Revista Multidisciplinar e de Psicologia. V.14, N. 50 p. 366-379, Maio/2020 